\title{
Study the Role of Prometheus Index in Prediction of Response to Treatment in Hepatitis C Patients of Genotype 4
}

\author{
Mohammad N El Khashab ${ }^{1}$, Mohammad Emam ${ }^{1}$, Marian Assad ${ }^{2}$, \\ Sahar A El Nemr ${ }^{1}$, Ahmed M Abd Elraziq ${ }^{1}$ \\ ${ }^{1}$ Tropical Medicine Department, Faculty of Medicine, Zagazig University, Egypt \\ ${ }^{2}$ Medical Microbiology and Imunology Department, Faculty of Medicine, Zagazig University, \\ Egypt
}

Corresponding Author: Ahmed M Abd Elraziq

Mobile+20100875872

4:

E mail:

a.mm36@yahoo.com

Key words: interferon- $\alpha$, ribavirin, interleukin $28 B$, viruses, HCV genotype, HCV viral load
Background and study aim : Because of pegylated interferon (Peg-IFN)/ribavirin therapy is poorly tolerated and rates of response are lower in hepatitis $\mathrm{C}$ virus (HCV) infected patients of genotype 4, the recognition of predictors of response is a high priority in this population. We aimed to use a baseline noninvasive index to predict early virological response (EVR) to Peg-IFN/ribavirin in $\mathrm{HCV}$ infected individuals, the score included 4 variables: 2 host-related variables (IL28B SNP rs12979860 and liver stiffness) and 2 HCV-related variables (genotype and viral load)

Patients and Methods: 96 treatmentnaive $\mathrm{HCV}$-infected patients receiving PegIFN/ribavirin were analysed and predictive model was used. The areas under the receiver operating characteristic (AUROC) curves $(95 \% \mathrm{CI})$, sensitivity and specificity, as well as negative and positive predictive values, were calculated. Only individuals

\section{INTRODUCTION}

Hepatitis C virus (HCV) infects $>175$ million people worldwide and is the leading cause of end-stage liver disease in Western countries [1].

Egypt has the highest prevalence of HCV worldwide with $9 \%$ countrywide and up to $50 \%$ in certain rural areas [2].

Also it has the highest prevalence of $\mathrm{HCV}-4$, which is responsible for almost $90 \%$ of infections and is considered a major cause of chronic hepatitis, liver cirrhosis, hepatocellular carcinoma, and liver transplantation in the country [3]. The published studies estimate the overall rates of spontaneous resolution in acute $\mathrm{HCV}-4$ infections to range who had completed a course of Peg-IFNRBV therapy were considered.

Results: EVR was achieved in $(60.4 \%)$ of patients. The area under the receiver operating characteristic curve (AUROC) was $0.849(0.762-0.914)$. Using three cutoff values, maximum specificity and sensitivity were $81.5 \%$ and $77.5 \%$, respectively, with a negative predictive value for EVR of $80 \%$ and a positive predictive value of $83.6 \%$. Seventeen individuals were misclassified using optimal cut-off values.

Conclusion: The probability of achieving EVR with Peg-IFN-RBV therapy in HCVinfected patients can be reliably estimated prior to initiation of therapy using Prometheus index that includes 4 noninvasive parameters. Prometheus index represents a reliable and easily applicable tool to individually evaluate the probability of achieving an EVR to Peg-IFN/ribavirin among HCV-infected patients.

between $20 \%$ and $50 \%$, which is not historically different than other genotypes [4]. The fibrosis progression rate in patients with chronic HCV-4 was 0.1-0.06 fibrosis units per year, with significantly higher grading and staging scores in Egyptian patients infected with HCV-4 [5].

Before the major and rapid advances in direct-acting antivirals, the standard of care (SOC) treatment consists of (pegylated) interferon-Alfa and ribavirin. However, depending on the viral genotype, treatment response rates differ significantly among infected patients. While up to $80 \%$ of the genotype 2 and 3 infected and $40-50 \%$ in genotype 1 patients can be cured, the response rate of genotype 4 in many clinical 
reports showed SVR rates exceeding 60\% [2]. There is no dought that the high treatment cost presents a high economic burden in developing country like Egypt, necessitating a more meticulous research on predictors of (SOC) treatment response. Such as viral factors as viral load, genotype and host factors as steatosis, gender, liver cirrhosis and genetics as IL28 polymorphisms. Viral Characteristics (viral load, genotype, viral variants for example within the interferon sensitivity determining region, ISDR) may be responsible for these differences but also other clinical parameters (age, gender, BMI, fibrosis stage, liver enzymes) have been shown to be associated with virological response [6].

The estimation of the probability of response to treatment against hepatitis $\mathrm{C}$ virus (HCV) with pegylated interferon- $\alpha$ (Peg-IFN) plus ribavirin has a high clinical impact. Better selection of candidates for HCV therapy is very important to special populations with lower response rates. Precise identification of patients with a very low likelihood of achieving response could help us to more properly manage a treatment with frequent and sometimes severe side effects. Thus, in patients with a very low probability of EVR treatment could be deferred until more effective combinations, including new direct-acting antivirals (DAAs), become approved in HCV infection. Conversely, patients with a high probability of EVR should be treated with current regimen [7]. Thus, a reliable tool to easily predict the probability of EVR is very useful in current clinical practice. Among the pre-treatment predictors of outcome that have been identified, HCV genotype, baseline plasma HCV RNA load and host genetic variations are highly predictive of response [8-10]. In this context, the singlenucleotide polymorphism (SNP) rs12979860 near the interleukin 28B (IL28B) gene has recently been independently associated with the response in $\mathrm{HCV}$-infected patients [8,9]. In SNPs, the $\mathrm{C}$ allele has a beneficial effect but homozygous TT or the heterozygous CT genotype have lower response rates compared with $\mathrm{CC}$ genotype carriers. Interestingly, a synergistic effect between these SNPs has been observed in HCV genotype 4 carriers [10]. Thus, HCV-infected individuals with favourable IL28B genotypes show a response rate of $70 \%$, while only $14 \%$ of those who present a combination of both genotypes other than CC achieve the response [10]. The combination of several predictors is important to enhance the predictive capacity of isolated factors [11,12].
However, the use of the predictive tools currently available is limited due to incomplete accuracy or because they use parameters not accessible everywhere or invasive [11,12]. It is therefore important to use a predictive model that allows reliable determination of the probability of response to Peg-IFN/ribavirin in HCV-infected patients. To overcome the drawbacks of the currently available predictive tools to forecast response to Peg-IFN/ribavirin in $\mathrm{HCV}$-infected patients, we aimed to use a new model using novel predictors of SVR, the determination of which is both simple and inexpensive, in order to facilitate HCV therapy decisions in such a population.

In this study, we investigated whether the Prometheus index can be used in its current form to predict responses in chronic HCV monoinfected genotype4 patients treated with the standard of care treatment.

\section{PATIENTS AND METHODS}

\section{Study patients}

96 naïve HCV infected patients older than 18 years who started treatment between February 2013 and October 2014 were included in this prospective study. Data to be used in the model were collected from a cohort followed in Tropical Medicine Department, the Scientific and Medical Research Center, Faculty of Medicine, Zagazig University Hospital and the regional treatment center for viral hepatitis (Ahrar Hospital) in Sharkia Governorate, Egypt. Naïve HCV patient older than 18 years were enrolled in the study. Those who voluntarily dropped out or discontinued therapy due to adverse events were excluded from the study population in order to analyse data using an on-treatment approach. Likewise, patients in whom HCV, IL28B genotype could not be determined were excluded from the analysis. Clinical visits were scheduled every 4 weeks during the first 12 weeks of treatment according to a pre-defined protocol. All patients were prospectively followed and data were collected in real time.

\section{Drug therapy}

Treatment regimens included pegIFN alpha 2a or $2 \mathrm{~b}$ at standard doses $(180 \mathrm{mg} / \mathrm{week}$ or 1.5 $\mathrm{mg} / \mathrm{kg} /$ week, respectively) plus weight-adjusted RBV dosing (1000 mg/day for patients weighing $<75 \mathrm{~kg}$ and $1200 \mathrm{mg} /$ day for patients weighing $\geq 75 \mathrm{~kg}$ ). Carriers of $\mathrm{HCV}$ genotype 4 were treated for 48 weeks [13]. Treatment duration 
and stopping rules were applied according to the Egyptian National Program for Prevention of $\mathrm{HCV}$ infection. EVR was defined as $2 \log$ or greater decline in HCV RNA by week 12 .

All patients were subjected to the following :

\section{Plasma HCV RNA and genotyping determination}

The plasma HCV RNA was determined by a quantitative PCR assay according to the technique available at the time when the patient was treated [Cobas TaqMan (Roche Diagnostic Systems Inc., Pleasanton, CA, USA), detection limit of $10 \mathrm{IU} / \mathrm{mL}]$. HCV genotyping was done using INNO-LiPA III (line immunoprobe assay) provided by Innogenetics, Ghent, Belgium.

\section{Liver fibrosis stage :}

The extent of hepatic fibrosis was measured using transient elastography by FibroScan (Echosens). Liver stiffness values are expressed in kilopascals (kPa).

For clinical purposes, stages of liver fibrosis were defined according to evaluations performed in $\mathrm{HCV}$-infected patients [14,15], using the Metavir score as follows: F0-F1, $<7.2 \mathrm{kPa}$; F2, $7.2-9.5 \mathrm{kPa}$; F3, 9.6-14.5 kPa; and F4, >14.5 kPa.

\section{rs12979860 genotyping :}

DNA was extracted from cryopreserved whole blood using G-spin ${ }^{\mathrm{TM}}$. Total DNA extraction kit (iNtRON Biotechnology, Korea) according to the manufacturer's instructions PCR-CTPP; The reactions were performed in $20 \mu$ l reaction mixtures using Maxime PCR PreMix Kit ( $i$-Taq) (iNtRON Biotechnology, Korea) ready to go PCR beads. Twenty $\mu \mathrm{M}$ of each primer were added. All primers were supplied from The Midland Certified Reagent Company Inc., Texas.

PCR reactions were performed using Veriti 96well thermal cycler (Applied Biosystems, Singapore). The researchers responsible for genotyping were blinded to the treatment outcome of the patients [16-18].

\section{Patients were divided according to response to} (SOC) therapy into two groups:

- Group I (Responders): included patients who achieved 2 log or greater decline in $\mathrm{HCV}$ RNA by week 12 (early virological response).

- Group II (Non Responders) : included patients who failed to achieve at least $2 \log$ decline in HCV RNA at the end of the 12 week: treatment was stopped.

\section{Statistical analysis}

Overall, results are presented as medians (lower and upper quartiles) for continuous variables and as frequencies and percentages for categorical data. Analysis of normality was performed using the Kolmogorov-Smirnov test. Categorical data and proportions were analyzed using the $\mathrm{X}^{2}$ test or the Fisher's exact test, as required. Student's $t$ test was used to compare the means of the 2 groups with normal distributions, and the MannWhitney U test was used to compare variables with non normal distributions. The study population was represented by all $\mathrm{HCV}$-infected individuals who had completed 12 weeks of pegIFN-RBV therapy and for whom baseline liver stiffness and IL28B genotyping results were available. Multiple association tests were conducted using univariate logistic regression to identify independent variables associated with EVR. In the last analysis, we included all variables with $\mathrm{P}$ values $<0.05$ in the univariate analysis. Then, a forward stepwise logistic regression analysis was conducted with $\mathrm{P}$ values for entry and exit of 0.05 and 0.10 , respectively. Thereafter, to express the likelihood of achieving EVR as a probability ranging from 0 to 1 , an index to predict EVR was used [19]. The accuracy of this index was obtained and compared by calculating area under the receiver operating characteristic (AUROC) curves. Criteria to qualify for accuracy were as follows: $0.90-1$ $=$ excellent, $0.80-0.90=$ good, $0.70-0.80=$ fair, and $0.60-0.70=$ poor

The ability of the predictive index to discriminate between EVR and non-EVR was assessed using several cutoffs. For obtaining the highest sensitivity and negative predictive value (NPV), the lowest cutoff was established at quartile 0.25 . Conversely, for obtaining the highest specificity and positive predictive value (PPV), the highest cutoff was established at quartile 0.75 . Finally, an intermediate cutoff fitting both the highest sensitivity and the highest specificity was established at quartile 0.5 .

The diagnostic odds ratio (DOR), which expresses the strength of the association between test results and disease, was also determined. Briefly, DOR is the ratio of the odds of a positive result in a given person with the target condition, compared with a person without the condition [19]. A DOR of 1 suggests that the test provides no diagnostic evidence. Finally, the likelihood ratios (LRs), which describe how many times a person with the target condition is more likely to have a particular test result, compared with a 
person without the condition, were also calculated. LRs contribute to change, after the test has been made, the probability that a target condition is present. Binary tests have 2 LRs, positive and negative. A LR of 1 indicates no diagnostic value.

All tests were 2-tailed, with $\mathrm{P}$ values $<0.05$ considered significant. All statistical analyses were performed using SPSS, version 16.0 (SPSS) and Stata, version 9.1 (Stata Corp).

\section{RESULTS}

\section{Main characteristics of the study population}

110 patients were included in this study. 14 (12.7\%) patients had been excluded due to voluntary drop-out and discontinuation caused by adverse effects. In the overall population, 44 (45.8\%) of the patients have IL28B genotype CC, 43 (44.8\%) genotype CT and 9 (9.4\%) genotype TT. The main baseline characteristics of the two studied groups are presented in Table (1).

\section{Response to $\mathrm{HCV}$ therapy}

EVR was achieved by $58(60.4 \%)$ patients. In the Responders, 33 (56.9\%) of those patients with IL28B genotype CC versus 22 (37.9\%) patients with IL28B genotype CT and 3 (5.2\%) patients with IL28B genotype TT. In the studying group, patients who achieved EVR showed a mean HCV RNA load at baseline of $1249400.41 \mathrm{IU} / \mathrm{mL}$ compared with 1413309.03 $\mathrm{IU} / \mathrm{mL}$ for those who did not achieved EVR.

\section{Diagnostic accuracy to predict SVR.}

Using the lowest cutoff (0.25), 20 patients in our study were correctly identified as nonresponders (true-negative findings without SVR), with 3 misclassified patients (false-negative findings with EVR) (Table 3).

Thus, lack of EVR was predicted with $86.9 \%$ certainty (NPV). The negative LR was 0.10 , and the DOR was 20. For the derivation and the validation cohort, values for sensitivity, NPV, negative LR, and DOR were similar to those obtained for the our study.

Using the highest cutoff (0.75), 30 patients in our study were correctly identified as responders (true-positive findings with EVR), with 4 patients misclassified (false-positive findings without SVR) (Table 3). Thus, EVR was predicted with $88.2 \%$ certainty (PPV). The positive LR was 4.9, and the DOR was 9.1. For the derivation and the validation cohort, values for specificity, NPV, negative LR, and DOR were similar to those obtained for our study.

When the intermediate cutoff $(0.50)$ was used in our study, 76 patients were correctly identified (45 true-positive findings and 31 true-negative findings), leaving 20 patients misclassified (7 false-positive findings and 13 false-negative findings) (Table 3). Thus, certainty for achieving EVR or not achieving SVR was $86.5 \%$ and $70.4 \%$, respectively. The DOR was 15.3 . For the derivation and the validation cohort, values for sensitivity, specificity, PPV, NPV, positive LR, negative LR, and DOR were similar to those obtained for our study. 
Table (1) : Baseline characteristics of the overall study population

\begin{tabular}{|c|c|}
\hline Variable & Value \\
\hline Age: years mean \pm SD (Range) & $44.84 \pm 8.39(21-59)$ \\
\hline BMI: $\mathbf{K g} / \mathbf{m}^{2}$ mean \pm SD (Range) & $25.32 \pm 1.83(21-29)$ \\
\hline $\begin{array}{l}\text { Sex:Male: } \mathrm{N}(\%) \\
\text { Female: } \mathrm{N}(\%)\end{array}$ & $\begin{array}{l}56(58.3 \%) \\
40(41.7 \%)\end{array}$ \\
\hline $\begin{array}{l}\text { Comorbidity:No: N(\%) } \\
\text { D.M: N(\%) } \\
\text { HPT: N(\%) }\end{array}$ & $\begin{array}{c}73(76 \%) \\
12(12.5 \%) \\
11(11.5 \%) \\
\end{array}$ \\
\hline WBCs: X1000mean \pm SD $(\mathrm{N}=3.9-10.7)$ & $8.59 \pm 2.11$ \\
\hline Hb:g/dl mean $\pm \mathrm{SD}(\mathrm{N}=14-17 \mathrm{~g} / \mathrm{dL})$ & $13.81 \pm 1.28$ \\
\hline Platelets:X1000mean \pm SD $(\mathrm{N}=150-350)$ & $205.65 \pm 39.71$ \\
\hline TSH:IU/Lmean \pm SD $(\mathrm{N}=0.5-5.0 \mu \mathrm{IU} / \mathrm{m} \mathrm{L})$ & $2.2 \pm 0.99$ \\
\hline AFP:IU/Lmean \pm SD $(\mathrm{N}=0-20 \mathrm{ng} / \mathrm{dL})$ & $5.86 \pm 3.04$ \\
\hline FBS: $\mathbf{m g} /$ dlmean \pm SD $(\mathrm{N}=70-100)$ & $93.82 \pm 11.65$ \\
\hline ALP:IU/Lmean \pm SD (N=36-92 IU/L) & $95.74 \pm 20.57$ \\
\hline ALT:IU/Lmean \pm SD (N=0-35 IU/L) & $70.72 \pm 13.89$ \\
\hline AST:IU/Lmean \pm SD (N=5-35 IU/L) & $59.69 \pm 9.01$ \\
\hline Albumin: g/dlmean $\pm \mathrm{SD}(\mathrm{N}=3.5-5.5 \mathrm{~g} / \mathrm{dL})$ & $4.26 \pm 0.52$ \\
\hline Bilirubin: $\mathbf{m g} / \mathrm{dlm}$ ean $\pm \mathrm{SD}(\mathrm{N}=0.3-1.2 \mathrm{mg} / \mathrm{dL})$ & $0.73 \pm 0.21$ \\
\hline Createnin: $\mathbf{m g} / \mathrm{dlmean} \pm \mathrm{SD}(\mathrm{N}=0.7-1.3 \mathrm{mg} / \mathrm{dL})$ & $0.88 \pm 0.25$ \\
\hline $\begin{aligned} \text { PCR: } \text { mean } \pm \text { SD } & \\
& >600000: \mathrm{N}(\%) \\
& \leq 600000: \mathrm{N}(\%)\end{aligned}$ & $\begin{array}{c}1762700 \pm 3134400 \\
39(40.6 \%) \\
57(59.4 \%) \\
\end{array}$ \\
\hline $\begin{array}{ll}\text { Fibro-scane: } & <7.2: \mathrm{N}(\%) \\
& <9.5: \mathrm{N}(\%) \\
& <14.5: \mathrm{N}(\%) \\
& >14.5: \mathrm{N}(\%)\end{array}$ & $\begin{array}{c}25(26 \%) \\
44(45.8 \%) \\
26(27.2 \%) \\
1(0.9 \%)\end{array}$ \\
\hline $\begin{array}{l}\text { CC: } \mathrm{N}(\%) \\
\text { CT: } \mathrm{N}(\%) \\
\text { TT:N(\%) } \\
\end{array}$ & $\begin{array}{c}44(45.8 \%) \\
43(44.8 \%) \\
9(9.4 \%) \\
\end{array}$ \\
\hline $\begin{array}{ll}\text { INF type: } & \text { a: } \mathrm{N}(\%) \\
& \text { b: } \mathrm{N}(\%)\end{array}$ & $\begin{array}{l}64(66.7 \%) \\
32(33.3 \%)\end{array}$ \\
\hline
\end{tabular}

This table shows that the age of the studied group was ranged from 21 to 59 years with mean 44.48 years. Body mass index (BMI) was ranged from 21 to $29 \mathrm{Kg} / \mathrm{m} 2$ with mean 25.23 . $58.3 \%$ of the studied group was male. Finally $76 \%$ of the cases had no comorbidity associated with HCV.

This table also shows that the studied group had normal WBCs, hemoglobin ( $\mathrm{Hb})$, platelets, thyroid stimulating hormone (TSH), alpha feto protein (AFP), fasting blood sugar (FBS), alkaline phosphatase (ALP), serum albumin, Bilirubin, Createnin level. But Alanine transaminase (ALT) and Aspartate transaminase (AST) were abnormally elevated. Regarding PCR $59.4 \%$ of the cases were less than $600000.45 .8 \%$ of the cases were less than $9.5 \mathrm{kpa}$ by fibro-scan. Regarding IL28B genotype study showed that most of the cases were $\mathrm{CC}$ and $\mathrm{CT}(45.8 \%$ \& $44.8 \%)$ respectively. Finally regarding INF type $66.7 \%$ of the cases were type a. 
Table (2) : Comparison between responder \& Non responder as regard pretreatment PCR viral load, IL28B SNP rs12979860, fibroscan

\begin{tabular}{|c|c|c|c|c|c|c|}
\hline Variable & \multicolumn{2}{|c|}{$\begin{array}{c}\text { Non responders } \\
\quad(n=38)\end{array}$} & \multicolumn{2}{|c|}{$\underset{(n=58)}{\text { Responders }}$} & MW & $\mathbf{p}$ \\
\hline $\begin{array}{l}\text { PCR:Mean } \\
\text { SD }\end{array}$ & \multicolumn{2}{|c|}{$\begin{array}{l}1413309.03 \\
2940130.56\end{array}$} & \multicolumn{2}{|c|}{$\begin{array}{l}1249400.41 \\
3041354.60\end{array}$} & 1056 & $\begin{array}{l}0.75 \\
\text { N.S }\end{array}$ \\
\hline \multirow{2}{*}{$\begin{array}{l}\text { PCR: } \\
>600000 \\
\leq 600000\end{array}$} & No & $\%$ & No & $\%$ & $\chi^{2}$ & \multirow[b]{2}{*}{$\begin{array}{l}0.30 \\
\text { N.S }\end{array}$} \\
\hline & $\begin{array}{l}13 \\
25\end{array}$ & $\begin{array}{l}34.2 \\
65.8\end{array}$ & $\begin{array}{l}26 \\
32\end{array}$ & $\begin{array}{l}44.8 \\
55.2\end{array}$ & 1.07 & \\
\hline $\begin{array}{l}\text { INF type: } \\
\text { a } \\
\text { b }\end{array}$ & $\begin{array}{l}22 \\
16 \\
\end{array}$ & $\begin{array}{l}57.9 \\
42.1 \\
\end{array}$ & $\begin{array}{l}42 \\
16 \\
\end{array}$ & $\begin{array}{l}72.4 \\
27.6 \\
\end{array}$ & 2.18 & $\begin{array}{l}0.14 \\
\text { N.S }\end{array}$ \\
\hline $\begin{array}{l}\text { IL28B: } \\
\text { CC } \\
\text { CT } \\
\text { TT } \\
\end{array}$ & $\begin{array}{c}11 \\
21 \\
6 \\
\end{array}$ & $\begin{array}{l}28.9 \\
55.3 \\
15.8 \\
\end{array}$ & $\begin{array}{c}33 \\
22 \\
3 \\
\end{array}$ & $\begin{array}{c}56.9 \\
37.9 \\
5.2 \\
\end{array}$ & 8.12 & $\begin{array}{c}\mathbf{0 . 0 2}^{*} \\
\mathrm{~S} \\
\end{array}$ \\
\hline $\begin{array}{l}\text { Fibroscane: } \\
<7.2 \\
<9.5 \\
<14.5 \\
\geq 14.5 \\
\end{array}$ & $\begin{array}{c}13 \\
14 \\
11 \\
0 \\
\end{array}$ & $\begin{array}{c}34.3 \\
36.8 \\
28.9 \\
0 \\
\end{array}$ & $\begin{array}{c}12 \\
30 \\
15 \\
1 \\
\end{array}$ & $\begin{array}{c}20.7 \\
51.7 \\
25.9 \\
1.7 \\
\end{array}$ & $\begin{array}{l}2.18 \\
2.68 \\
0.11 \\
0.66 \\
\end{array}$ & $\begin{array}{l}0.14 \text { N.S } \\
0.10 \text { N.S } \\
0.74 \text { N.S } \\
0.42 \text { N.S }\end{array}$ \\
\hline $\begin{array}{l}\text { Prometheus index } \\
0-\leq 0.25 \\
>0.25-\leq 0.50 \\
>0.50-\leq 0.75 \\
>0.75-1.0\end{array}$ & $\begin{array}{c}20 \\
11 \\
3 \\
4\end{array}$ & $\begin{array}{c}52.6 \\
28.9 \\
7.9 \\
10.5\end{array}$ & $\begin{array}{c}3 \\
10 \\
15 \\
30\end{array}$ & $\begin{array}{c}5.2 \\
17.2 \\
25.9 \\
51.8\end{array}$ & $\begin{array}{c}\mathbf{2 8 . 3 8} \\
1.84 \\
\mathbf{4 . 8 7} \\
\mathbf{1 5 . 2 8}\end{array}$ & $\begin{array}{c}\mathbf{0 . 0 0 0} * * \mathbf{H S} \\
0.17 \text { N.S } \\
\mathbf{0 . 0 3}^{*} \mathbf{S} \\
\mathbf{0 . 0 0 0} * \mathbf{H S}\end{array}$ \\
\hline
\end{tabular}

This table shows that there were statistical significance differences between responders and non responders in IL28 B genotype and Prometheus index. But there were no statistical significance differences between them in PCR level, INF type or fibrocsane results. 


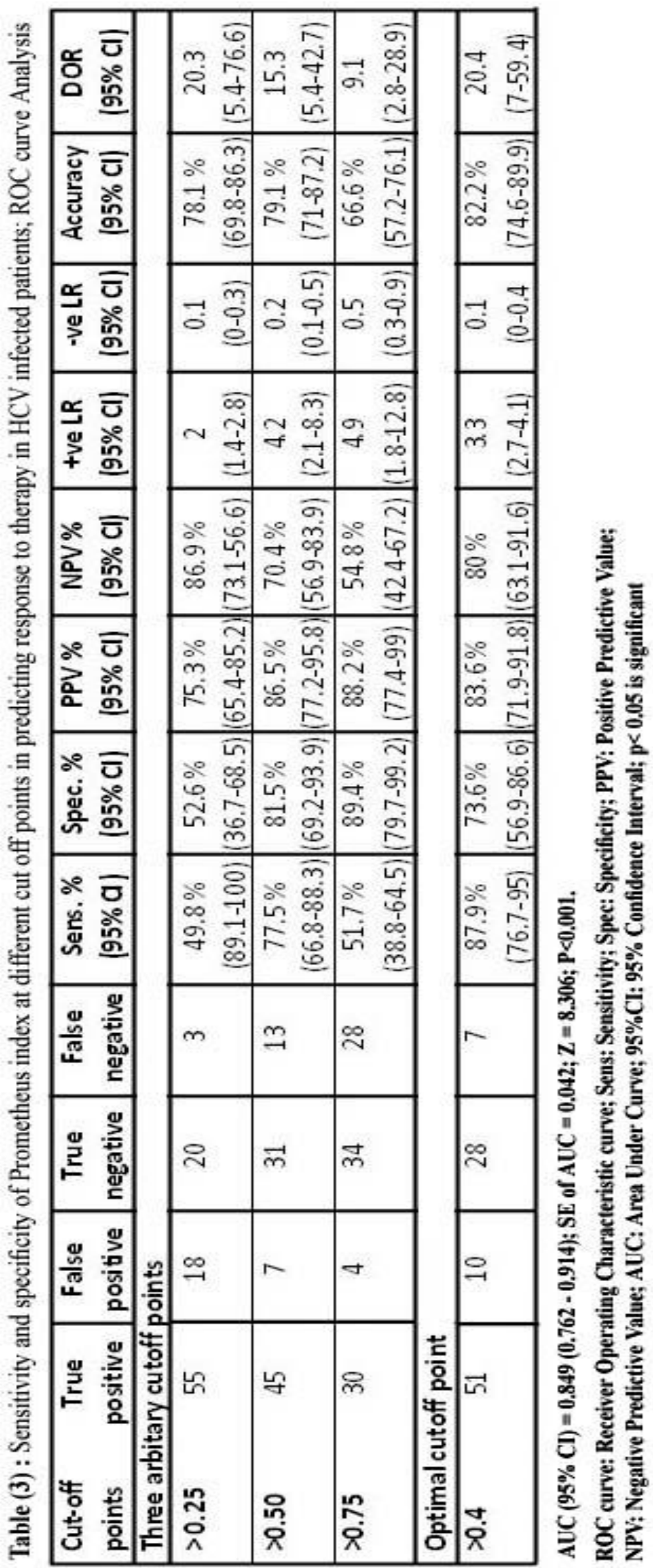

El-Khashab et al., Afro-Egypt J Infect Endem Dis 2015; 5(4):207-217 http://mis.zu.edu.eg/ajied/home.aspx 


\section{ROC Curve}

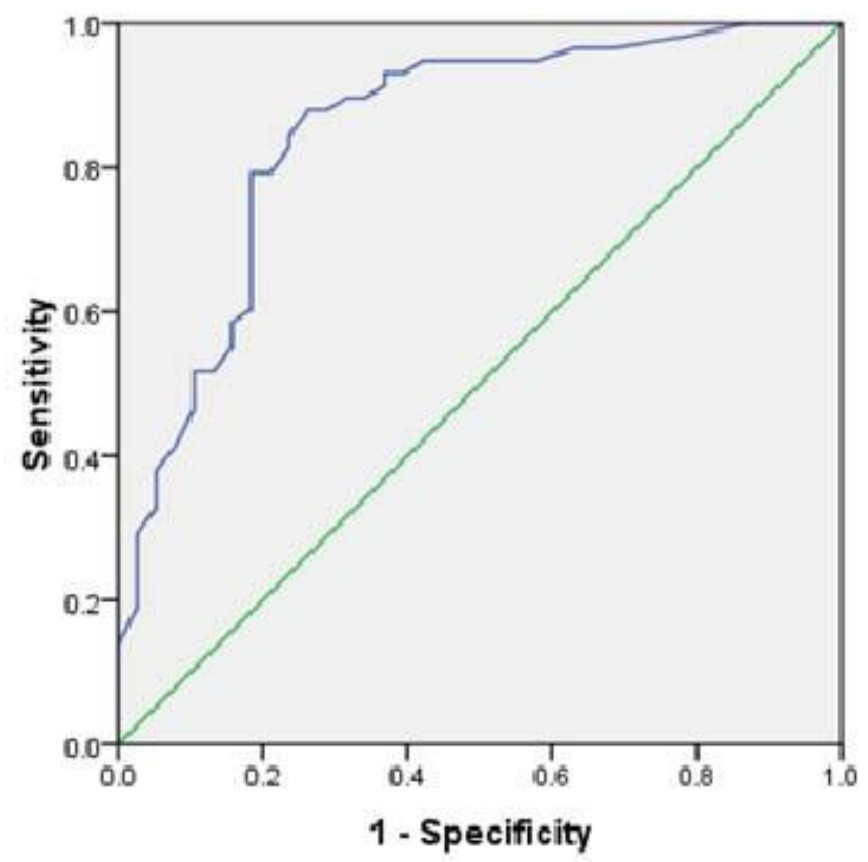

Fig. (1) : Receiver operating characteristic (ROC) curve of Prometheus index as a predictor for EVR in HCV infected patients treated by standard care of therapy (SOC).

This figure shows the sensitivity and specificity of PI as a predictor for EVR in HCV infected patients treated by SOC at different cut off points. The area under curve were 0.85 with CI $(0.77-0.93)$ with $p$ value $=0.00$.

\section{DISCUSSION}

Before the major and rapid advances in directacting antivirals, the accurate prediction of response to pegIFN-RBV before initiation of treatment is very important for the identification of potentially curable HCV infected patients. For this goal, the Prometheus index which incorporated 4 variables: 2 host-related variables (IL28B SNP rs12979860 and liver stiffness) and $2 \mathrm{HCV}$ related variables (genotype and viral load) has been used to predict the response to SOC therapy in HCV-HIV coinfected patients. In the present study, using the lowest cutoff $(0.25), 20$ patients were correctly identified as nonresponders (truenegative findings without EVR), with 3 misclassified patients (false-negative findings with EVR). Thus, lack of EVR was predicted with $86.9 \%$ certainty (NPV). The negative LR was 0.10 , and the DOR was $\sim 20$. These results were in agreement with those obtained by Medrano et al.(2010) for the derivation and the validation cohort [11].
In the present study, using the highest cutoff (0.75), 30 patients were correctly identified as responders (true-positive findings with EVR), with 4 patients misclassified (false-positive findings without EVR). Thus, EVR was predicted with $88.2 \%$ certainty (PPV). The positive LR was 4.9 , and the DOR was 9.1. These results were in agreement with those obtained by Medrano et al. for the derivation and the validation cohort [11].

In the present study, when the intermediate cutoff $(0.50)$ was used, 76 patients were correctly identified (45 true-positive findings and 31 truenegative findings), leaving 20 patients misclassified ( 7 false-positive findings and 13 false-negative findings). Thus, certainty for achieving EVR or not achieving EVR was $86.5 \%$ and $70.4 \%$, respectively. DOR was 15.3. These results were in agreement with those obtained by Medrano et al. for the derivation and the validation cohort [11].

Also these results were in agreement with those obtained by Neukam et al. who used a model combining HCV genotype, baseline HCV RNA load, interleukin 28B and low-density lipoprotein 
receptor (LDLR) genetic variations to predict response to Peg-IFN/ribavirin in $\mathrm{HIV} / \mathrm{HCV}$ coinfected individuals [20]. They reported that using two cut-off values in their model, maximum specificity and sensitivity were $89.7 \%$ and $96.6 \%$, respectively, with a negative predictive value of $88.9 \%$ and a positive predictive value of $83.6 \%$. Thirteen $(7.2 \%)$ individuals were misclassified [20]. But their study has three limitations. First, the determination of the LDLR genotype is not a standard procedure in clinical practice. Second, only one SNP of the LDLR gene was incorporated in this model. Finally, the model was not validated in HCV-monoinfected patients. Critical differences in the characteristics of HIV/HCV-coinfected patients may lead to a different response profile and the effectiveness of the model in a monoinfected population may be satisfactory. Also these results were in agreement with those obtained by Neukam et al. who used the algorithm in patients classified as anticipated or unlikely responders according to HCV genotype, baseline plasma HCV RNA concentration above or below $600000 \mathrm{IU} / \mathrm{mL}$ and IL28B genotype [12]. They reported that using their algorithm, maximum specificity and sensitivity were $67.4 \%$ and $86.2 \%$, respectively, with a negative predictive value of $82.7 \%$ and a positive predictive value of $73 \%$, but $86(23.1 \%)$ individuals were misclassified [12]. It is noted that, a considerably high percentage of patients remained unclassified when this algorithm was applied, specifically $42 \%$ of genotype 1 carriers and $38 \%$ of genotype 4 carriers. In contrast, the Prometheus index used here in the present study, is applicable in all patients since it enables the calculation of a precise probability for each individual and thus represents a clear advantage over treatment algorithms. In this way, the contribution to individual treatment decisions using this application is higher.

The area under the receiver operating characteristic (AUROC) curve values of the present study was $(95 \% \mathrm{CI})=0.849(0.762-0.914)$ indicating that the diagnostic performance of the model was good. This result was in agreement with that obtained by Medrano et al. who reported that using the Prometheus index, AUROC curve values were 0.89 in the derivation group and 0.85 in the validation group [11].

Also the diagnostic performance of the Prometheus index used in the present study was in agreement with that obtained by Neukam et al. who reported that using their model, AUROC curve values $(95 \% \mathrm{CI})$ were $0.83(0.77-0.89)$ for the development group and $0.84(0.77-0.91)$ for the validation group [20]. While the diagnostic performance of the model in the present study was not in agreement with that obtained by Medrano and Fishbein [21] who found that the Prometheus index was worse at predicting treatment outcome in $\mathrm{HCV}$ monoinfected patients (AUROC, $0.77 ; 95 \%$ CI 0.70 to $0.84 ; \mathrm{P}=.01$ ) than in HIV/HCV coinfected patients (AUROC, $0.87 ; 95 \%$ CI 0.83 to $0.92 ; \mathrm{P}=.01$ ).

This difference can be explained by the fact that there were different group of patients in our study in comparison to Medrano and Fishbein [21] where our patients were of genotype 4 instead of other genotypes in Medrano et al. study, also we use EVR not SVR as end point for evaluation of predicting the performance.

The diagnostic performance of the model in the present study was not in agreement with that obtained by Neukam et al. who reported that using their algorithm, AUROC curve values $(95 \% \mathrm{CI})$ were $0.77(0.733-0.814)$ for the elaboration group, $0.77(0.708-0.841)$ for the validation group and $0.77(0.733-0.814)$ for the overall population [20]. The predictive performance of the algorithm developed by Neukam et al. is lower than that yielded by the Prometheus index. This difference can be explained by the fact that the algorithm was conducted on considerably small proportion of genotype 4 carriers. Also the algorithm was conducted on HIV/HCV-coinfected patients.

Generally, the Prometheus index has some limitations for usage as a good predictors for response to standard of care therapy for $\mathrm{HCV}$ treatment e.g the elastography is new procedure, not available in many centers even those which are specialized in management of HCV patients, also elastography was not approved as a standard procedure for evaluation of fibrosis stage in $\mathrm{HCV}$ patients except recently [22]. Also, Prometheus index will be obsolete in the near future, with era of DAA drugs and IFN free therapy.

In conclusion, in the present study Prometheus index allowed reliable determination of the probability of outcome to Peg-IFN/ribavirin in HCV-monoinfected patients using simple items. Its application in clinical practice could aid treatment decisions and represents a further step towards individualization of therapy against $\mathrm{HCV}$.

Funding: None.

Conflicts of interest: None. 
Ethical approval: The protocol of the study was approved by the Ethical Committee of Faculty of Medicine, Zagazig University and the Ethical Committees of the participating hospitals. Informed consents were obtained from all patients.

\section{Acknowledgement}

We acknowledge Scientific and Medical Research Center (ZSMRC) of Zagazig Faculty of Medicine for its support.

\section{REFERENCES}

1. Lauer G, Walker B. Hepatitis $\mathrm{C}$ virus infection. $N$ Engl J Med 2001; 345:41-52.

2. Kamal SM ,Nasser IA. Hepatitis C Genotype 4: What We Know and What We Don't Yet Know. Hepatology; 2008 47:1371-1383.

3. Abdel-Hamid M, El-Daly M, Molnegren V, ElKafrawy S, Abdel-Latif S, Esmat G, et al. Genetic diversity in hepatitis C virus in Egypt and possible association with hepatocellular carcinoma. Virology 2007; 88:1526-1531.

4. Kamal SM, Moustafa KN, Chen J, Fehr J, Abdel Moneim A, Khalifa KE, et al. Duration of peg-interferon therapy in acute hepatitis $\mathrm{C}$ : a randomized trial. Hepatology 2006;43:923-931.

5. Roulot D, Bourcier V, Grando V, Deny P, Baazia Y, Fontaine H, et al.; Observational VHC4 Study Group. Epidemiological characteristics and response to peginterferon plus ribavirin treatment of hepatitis $\mathrm{C}$ virus genotype 4 infection. J Viral Hepat 2007;14:460-467.

6. Kau A, Vermehren J, Sarrazin C. Treatment predictors of a sustained virologic response in hepatitis B and C. J Hepatol 2008;49:634-651.

7. Berenguer J, Alvarez-Pellicer J, Martín PM, López-Aldeguer J, Von-Wichmann MA, Quereda $\mathrm{C}$, et al. Sustained virological response to interferon plus ribavirin reduces liver-related complications and mortality in patients coinfected with human immunodeficiency virus and hepatitis C virus. Hepatology 2009; 50: 407-13.

8. Rallón N, Naggie S, Benito JM, Medrano J, Restrepo C, Goldstein D, et al. Association of a single nucleotide polymorphism near the interleukin-28B gene with response to hepatitis C therapy in HIV/ hepatitis C virus co-infected patients. AIDS 2010; 24:F23-9.

9. Pineda J, Caruz A, Rivero A, Neukam K, Salas I, Camacho A, et al. Prediction of response to pegylated interferon plus ribavirin by IL28B gene variation in patients coinfected with HIV and hepatitis C virus.Clin Infect Dis 2010;51:788-95.
10. Pineda J, Caruz A, Di Lello FA, Camacho A, Mesa P, Neukam K, et al. Low-density lipoprotein receptor genotyping enhances the predictive value of IL28B genotype in HIV/hepatitis C virus-coinfected patients. AIDS 2011; 25:1415-20.

11. Medrano J, Neukam K, Rallón N, Rivero A, Resino S, Naggie S, et al. Modeling the probability of sustained virological response to therapy with pegylated interferon plus ribavirin in patients coinfected with hepatitis $\mathrm{C}$ virus and HIV.Clin Infect Dis 2010;51: 1209-16.

12. Neukam K, Camacho A, Caruz A, Rallón N, Torres-Cornejo A, Rockstroh JK, et al. Prediction of response to pegylated interferon plus ribavirin in HIV/hepatitis $\mathrm{C}$ virus (HCV)-coinfected patients using HCV genotype, IL28B variations, and HCV-RNA load.J Hepatol 2012;56: 788-94.

13. NIH. National Institutes of Health Consensus Development Conference Statement: Management of Hepatitis C: 2002, June 10-12, 2002. Hepatology, 2002;36Suppl 1: S3-20.

14. de Lédinghen V, Douvin C, Kettaneh A, Ziol M, Roulot D, Marcellin P, et al. Diagnosis of hepatic fibrosis and cirrhosis by transient elastography in HIV/hepatitis C virus-coinfected patients. J Acquir Immune Defic Syndr 2006; 41:175-179.

15. Kirk GD, Astemborski J, Mehta SH, Spoler C, Fisher C, Allen D, et al. Assessment of liver fibrosis by transient elastography in persons with hepatitis $\mathrm{C}$ virus infection or HIV-hepatitis C virus coinfection. Clin Infect Dis 2009; 48:963972.

16. Sambrook J, Fritrsch EF and Maniatis $T$. Molecular Cloning, a Laboratory Manual, 2nd ed. Cold Spring Harbor Laboratory. Cold Spring Harbor, N.Y. 1989.

17. Hamajima N, Saito T, Matsuo K, Kozaki K, Takahashi T, Tajima K. Polymerase chain reaction with confronting two-pair primers for polymorphism genotyping. Jpn J Cancer Res 2000 ; 91(9): 865868.

18. Ferreira S, Abreu RM, da Silva MC, Ferreira AS, Nasser PD, Carrilho FJ, et al. A Fast and costeffective method for identifying a polymorphism of interleukin 28B related to hepatitis C. PLoS One 2013; 22;8(10):e78142.

19. Grimes D, Schulz K. Refining clinical diagnosis with likelihood ratios. Lancet 2005; 365:1500-1505.

20. Neukam K, Almeida C, Caruz A, Rivero-Juárez A, Rallón NI, Di Lello FA, et al. A model to predict the response to therapy against hepatitis $\mathrm{C}$ virus (HCV) including low-density lipoprotein receptor genotype in $\mathrm{HIV} / \mathrm{HCV}$-coinfected patients. J Antimicrob Chemother 2013 ;68(4):915-21. 
21. Medrano , Fishbein. Prometheus Index Predicts Hepatitis C Treatment Response; 19th Conference on Retroviruses and Opportunistic Infections (CROI): Abstract 761. Presented March 7, 2012.

22. EASL recommendations for HCV treatment, 2014.
Peer reviewers: Maysaa Saed ,Professor of Tropical Medicine and Hepatogastroenterology, Faculty of Medicine, Zagazig University, Egypt. Editor: Tarik Zaher, Professor of Tropical Medicine and Hepatogastroenterology, Faculty of Medicine, Zagazig University, Egypt 